\section{Case Reports in Neurology}

Case Rep Neurol 2020;12:189-195

DOI: 10.1159/000505390

Published online: December 14, 2020
(C) 2020 The Author(s)

Published by S. Karger AG, Basel www.karger.com/crn

This article is licensed under the Creative Commons Attribution-NonCommercial 4.0 International License (CC BY-NC) (http://www.karger.com/Services/OpenAccessLicense). Usage and distribution for commercial purposes requires written permission.

\title{
Late Diagnosis of Multiple Cerebral Aneurysms A Decade after Resection of Cardiac Myxoma
}

\author{
Swati Jain ${ }^{a}$ Vincent Diong Wen Nga ${ }^{a}$ \\ Narayanaswamy Venketasubramanian ${ }^{b}$ \\ aDivision of Neurosurgery, University Surgical Cluster, National University Health System, \\ Singapore, Singapore; ${ }^{b}$ Raffles Neuroscience Centre, Raffles Hospital, \\ Singapore, Singapore
}

\section{Keywords}

Cardiac myxoma $\cdot$ Cerebral aneurysms $\cdot$ Stroke $\cdot$ Embolism

\begin{abstract}
Cerebral embolism from a cardiac myxoma is a rare cause of ischaemic stroke. These emboli may later lead to the development of cerebral aneurysms. We report a case of delayed presentation of neurological manifestations in form of multiple intracranial aneurysms many years after treatment of a cardiac myxoma. Our patient, a 55-year-old right-handed female with a background history of hypertension, first presented at the age of 45 years with a sudden onset of right hemiplegia. A CT brain scan detected multiple infarcts in the territory of the left middle cerebral artery. Echocardiography revealed a cardiac myxoma for which she underwent immediate total surgical resection. Nearly 10 years after this diagnosis, she presented again with right-sided weakness and left ptosis. CT scan of the brain revealed bilateral acute superior cerebellar infarcts with interval evolution of previously known left cortical infarcts. MRI/MR angiogram showed multiple aneurysms arising from the bilateral middle, left anterior and left posterior cerebral arteries. She was managed conservatively. The management of multiple aneurysms with cardiac myxomas is highly debatable and dependent on the patient's presentation. This case highlights the importance to follow up on potential late extra-cardiac manifestations of the myxomas despite adequate resection.




\section{Case Reports in Neurology}

Case Rep Neurol 2020;12:189-195

DOI: $10.1159 / 000505390$

(c) 2020 The Author(s). Published by S. Karger AG, Basel www.karger.com/crn

Jain et al.: Cardiac Myxoma and Multiple Cerebral Aneurysms

\section{Introduction}

Cardiac myxoma is one of the most frequent cardiac tumours, arising from the subendocardial multipotential mesenchymal cells. They can be either in solid or papillary intracardiac masses, usually in the atria. These tumours undergo microhaemorrhages, which result in thrombus formation over time. These thrombi may embolise resulting in myriad of neurological complications $[1,2]$.

Up to two-thirds of the emboli travel to the central nervous system, resulting in nearly $25-45 \%$ of the neurological symptoms seen $[3,4]$. These symptoms range from ischaemic strokes, haemorrhages, headaches, to seizures. Of interest is the formation of intracranial aneurysms secondary to embolic phenomenon from these tumours. The pathophysiology responsible for the formation of these aneurysms is still not well understood. The temporal variability between the diagnosis of aneurysms and earlier treatment of cardiac myxomas remains unexplained.

We describe a patient who first presented with ischaemic stroke due to embolism from a cardiac myxoma. Nearly 10 years after excision of her myxoma, she presented with recurrent ischaemic strokes; her workup also revealed multiple intracranial aneurysms.

\section{Case Report}

A 55-year-old female, right-handed, first presented at the age of 45 year with a sudden onset of right-sided limb weakness without slurred speech or numbness. She was known to have a long-standing history of hypertension prior to this presentation with no other significant medical history of note especially of diabetes mellitus, hyperlipidaemia, heart disease, smoking, previous stroke or transient ischaemic attacks. Clinically, she was well, with no aphasia, anopia or neglect. She had a mild right-sided facial weakness and a dense right hemiplegia, with intact sensation. A CT scan of her brain revealed multiple embolic infarcts in the left middle cerebral artery (MCA) territory.

No intracranial vascular study was done at that juncture, but a transthoracic echocardiogram revealed a left atrial myxoma measuring $1.8 \mathrm{~cm} \times 5.8 \mathrm{~cm}$. She underwent an immediate total resection of the myxoma and recovered well post-operatively. She recovered well functionally and became independent in self-care.

Nearly 10 years after the presentation with her ischaemic stroke, she developed rightsided weakness again and left ptosis. Clinical examination revealed mild right face and limb weakness, partial left ptosis with intact pupil response to light, full eye movements, and bilateral limb ataxia. CT of the brain revealed bilateral acute superior cerebellar infarcts with interval evolution of previously known left cortical infarcts. MRI/MR angiogram showed multiple aneurysms arising from the cortical and insular branches of the MCAs bilaterally with the largest aneurysm arising from M2 of the right MCA measuring $9 \times 8 \mathrm{~mm}$. A $6 \times 6 \mathrm{~mm}$ dilatation was also noted from the left anterior cerebral artery, while a tubular dilatation was seen in the left posterior cerebral artery. A digital subtraction angiogram confirmed these findings (Fig. 1, 2). The aneurysms were radiologically characterised as thick walled and likely thrombosed. Echocardiography did not reveal recurrence of the myxoma.

In view of her clinical stability and the likely cause of multiple aneurysms being embolic in nature from known cardiac myxoma, the decision was made for conservative management of her aneurysms with serial imaging. She is being treated for her hypertension as well with

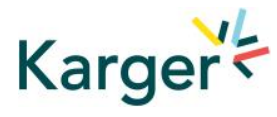




\section{Case Reports in Neurology}

Case Rep Neurol 2020;12:189-195

DOI: $10.1159 / 000505390$

(c) 2020 The Author(s). Published by S. Karger AG, Basel www.karger.com/crn

Jain et al.: Cardiac Myxoma and Multiple Cerebral Aneurysms

well controlled blood pressure on atenolol. She continues to be monitored on a regular basis with follow-up MR angiogram to evaluate for any further increase in size of the aneurysms or development of new ischaemic infarcts secondary to vessel occlusion.

\section{Discussion}

Cardiac myxomas present at a mean age of 50 years, with the greater proportion of the patients being females. Primarily found in the left atrial fossa (nearly 75\%), they can interfere with pulmonary and systemic circulation resulting in impaired valve function $[1,2,5,6]$. They may also spread haematogenously, resulting in varied systemic manifestations. Patients may present with myriad of neurological complications including embolic infarction, intracranial cerebral aneurysm formation, subarachnoid and intra-parenchymal haemorrhage.

Stoane et al. [7] proposed that tumour cells in the emboli lead to perivascular damage, resulting in pseudoaneurysm formation following the obstruction. Another hypothesis proposed by New et al. [8] is that of endothelial damage from tumour emboli resulting in an inflammatory response at the site of injury. There is subintimal growth, destruction of arterial growth and fibroblastic proliferation leading to progressive destruction of the wall with smooth muscle proliferation; they proposed a "neoplastic variety" of aneurysm. This may explain why there is progression of aneurysms despite resection of cardiac myxoma.

A more recent postulate is that tumour emboli get lodged into the vasa vasorum of the peripheral arteries, which eventually lead to weakening of the internal elastic lamina and subsequent aneurysm formation [9]. The histopathological study of general fusiform aneurysms by other reports also attributed a similar mechanism to aneurysm formation with deposition of lipid in and beneath the intima which disrupts the internal elastic lamina and infiltrates the muscular wall [10]. The rupture of the atheroma leads to the transmural extension of the thrombus and create the characteristic fusiform shape of the aneurysm.

Further reasons to support the hypothesis of tumour emboli deposition in vessel wall leading to aneurysmal dilatation are the endocrine and secretory properties of cardiac myxoma cells. They are well known to secrete interleukins such as IL-6 and metalloproteinases which have been postulated to be the cause of the constitutional symptoms experienced by the patients. These secretory products could contribute to the degradation of the extracellular matrix and promote the proliferation of the tumour cells within the vessel wall. Yaguchi et al. [11] measured levels of IL-6 in a 23-year-old patient who presented with multiple cerebellar haemorrhages and were noted to be high in the CSF. After resection of the cardiac myxoma, these IL-6 levels in CSF returned to normal and they have thus suggested the use of CSF levels of IL-6 as a marker for neurological manifestations of cardiac myxoma. Serum levels of IL-6 may also be elevated in patients with cardiac myxoma, which may serve as a more easily obtainable biomarker $[9,12]$.

In our patient, the presence as well as the extent of intracranial aneurysms was unknown at the time of diagnosis of cardiac myxomas. She was diagnosed with these intracranial aneurysms nearly a decade later. Ours is one of the few case reports in which the intracranial aneurysms were diagnosed nearly a decade after the initial presentation with a cardiac myxoma. Despite the benign nature of cardiac myxomas, metastasis of these tumours due to embolic phenomenon has been recognised as early as 1970 [8] with both local recurrence as well delayed presentation of metastatic embolisms years after resection of the primary tumour. Our patient underwent complete surgical resection of cardiac myxoma and remained

\section{Karger'=}




\section{Case Reports in Neurology}

Case Rep Neurol 2020;12:189-195

DOI: $10.1159 / 000505390$

(c) 2020 The Author(s). Published by S. Karger AG, Basel www.karger.com/crn

Jain et al.: Cardiac Myxoma and Multiple Cerebral Aneurysms

asymptomatic for nearly 10 years. Namura et al. [13] reported a case of a 45-year-old gentleman who presented with recurrent embolic strokes of unknown cause until a final evaluation revealed multiple cerebral aneurysms secondary to a cardiac myxoma detected 10 and 25 years, respectively, after initial presentation. A recent study [14] reported 2 cases of delayed detection of intracranial aneurysms with previously treated cardiac myxoma 14 and 18 years before. In keeping with our case study, intracranial complications can have delayed presentation despite treatment of cardiac myxoma.

Understanding of the progression of myxomatous aneurysms remains unknown especially after the resection of the cardiac myxoma. Considering the theories that suggest the deposition of tumour emboli into the vessel walls leading to vessel wall destruction and progression into aneurysms, aneurysm progression and formation will be expected to occur despite the treatment of the original myxoma $[1,15]$. However, whether these aneurysms continue to increase in size remains unknown. In our case study, the patient has been on follow-up with serial MR angiograms which have showed no change in the morphology of these aneurysms.

As can be seen from the angiogram results in the patient, the distribution of aneurysms was primarily concentrated in the MCA territory with involvement of the posterior and anterior circulation as well. This is in keeping with the current literature of the preferential distribution to the MCA territory as compared to atherosclerotic aneurysms that are limited to the vertebrobasilar circulation [16].

The management of aneurysms secondary to atrial myxoma is uncertain. While conservative management is the preferred choice, other options include microsurgery, clipping, coiling, radiotherapy and chemotherapy [17]. There are no randomised controlled trials to address this issue.

In conclusion, in a patient where the diagnosis of the cardiac myxoma is incidental, a detailed history should be elicited with regards to any presentation that is suggestive of a cerebral ischaemia. This would warrant further investigation for cerebral vessel involvement due to propensity of the emboli for intracranial deposition. On the other hand, if the patient's primary presentation is that of ischaemic stroke, initial workup is needed to look for a cardioembolic cause, including atrial myxoma. If brain imaging reveals multiple aneurysms, a cardiac evaluation is warranted to detect myxoma. Since even after surgical resection of the myxoma the possibility of having circulating emboli and aneurysmal development and growth continues, non-invasive evaluation of the cerebral arteries should be done on a regular basis to detect the presence of delayed formation of intracranial aneurysms. Further research into possible biomarkers such as IL-6 that are known to be secreted by the tumour cells could potentially help in monitoring of such patients.

\section{Acknowledgement}

The authors would like to acknowledge the patient for allowing us to use the clinical information for the publication of this case report.

\section{Statement of Ethics}

The subject for this case report has given the consent to use unidentified material for the purposes of this study. All the clinical data has been anonymized to prevent identification.

\section{Karger'=}




\section{Case Reports in Neurology}

Case Rep Neurol 2020;12:189-195

DOI: $10.1159 / 000505390$

(C) 2020 The Author(s). Published by S. Karger AG, Basel www.karger.com/crn

Jain et al.: Cardiac Myxoma and Multiple Cerebral Aneurysms

\section{Conflict of Interest Statement}

The authors have no conflicts of interest to declare.

\section{Funding Sources}

No funding sources were used for the purposes of this study.

\section{Author Contributions}

Swati Jain was responsible for gathering clinical data and writing this case report. Vincent Nga provided valuable contributions towards understanding the neurosurgical aspect of this case and reviewing the paper. Narayanaswamy Venketasubramanian provided key insights into understanding the complexity of follow-up and management of this case, guided the first author and reviewed the paper.

\section{References}

1 Desousa AL, Muller J, Campbell R, Batnitzky S, Rankin L. Atrial myxoma: a review of the neurological complications, metastases, and recurrences. J Neurol Neurosurg Psychiatry. 1978 Dec;41(12):1119-24.

2 Thyagarajan B, Kumar MP, Patel S, Agrawal A. Extracardiac manifestations of atrial myxomas. J Saudi Heart Assoc. 2017 Jan;29(1):37-43.

3 Li Q, Shang H, Zhou D, Liu R, He L, Zheng H. Repeated embolism and multiple aneurysms: central nervous system manifestations of cardiac myxoma. Eur J Neurol. 2008 Dec;15(12):e112-3.

4 Pérez Andreu J, Parrilla G, Arribas JM, García-Villalba B, Lucas JJ, Garcia Navarro M, et al. Neurological manifestations of cardiac myxoma: experience in a referral hospital. Neurologia. 2013 Nov-Dec;28(9):52934.

5 Branch CL Jr, Laster DW, Kelly DL Jr. Left atrial myxoma with cerebral emboli. Neurosurgery. 1985 May;16(5):675-80.

6 Walker MT, Kilani RK, Toye LR, Bird CR. Central and peripheral fusiform aneurysms six years after left atrial myxoma resection. J Neurol Neurosurg Psychiatry. 2003 Feb;74(2):281-2.

7 Stoane L, Allen JH Jr, Collins HA. Radiologic observations in cerebral embolization from left heart myxomas. Radiology. 1966 Aug;87(2):262-6.

8 New PF, Price DL, Carter B. Cerebral angiography in cardiac myxoma. Correlation of angiographic and histopathological findings. Radiology. 1970 Aug;96(2):335-45.

9 Ezerioha N, Feng W. Intracardiac Myxoma, Cerebral Aneurysms and Elevated Interleukin-6. Case Rep Neurol. 2015 Jul;7(2):152-5.

10 Barletta EA, Ricci RL, Silva RD, Gaspar RH, Araújo JF, Neves MW, et al. Fusiform aneurysms: A review from its pathogenesis to treatment options. Surg Neurol Int. 2018 Sep;9(1):189.

11 Yaguchi H, Murakami Y, Sengoku R, Sato H, Inoue K. [A case of cardiac myxoma presenting with multiple cerebellar hemorrhages and elevation of interleukin-6 in the cerebrospinal fluid]. Rinsho Shinkeigaku. 2004;44(10):677-81.

12 Sabolek M, Bachus-Banaschak K, Bachus R, Arnold G, Storch A. Multiple cerebral aneurysms as delayed complication of left cardiac myxoma: a case report and review. Acta Neurol Scand. 2005 Jun;111(6):345-50.

13 Namura O, Saitoh M, Moro H, Watanabe H, Sogawa M, Nishikura K, et al. A case of biatrial multiple myxomas with glandular structure. Ann Thorac Cardiovasc Surg. 2007;13(6):423-7.

14 Santillan A, Knopman J, Patsalides A, Pierre Gobin Y. Delayed intracranial aneurysm formation after cardiac myxoma resection: report of two cases and review of the literature. Interv Neuroradiol. 2019 Apr;25(2):177-81.

15 Stöllberger C, Finsterer J. Patients with cardiac myxoma require surveillance for myxoma-related cerebral aneurysms. Eur J Neurol. 2008 Dec;15(12):e110-1. 
Case Reports in Neurology
Case Rep Neurol 2020;12:189-195

DOI: $10.1159 / 000505390$

(c) 2020 The Author(s). Published by S. Karger AG, Basel www.karger.com/crn

Jain et al.: Cardiac Myxoma and Multiple Cerebral Aneurysms

16 Wen XY, Chen YM, Yu LL, Wang SR, Zheng HB, Chen ZB, et al. Neurological manifestations of atrial myxoma: A retrospective analysis. Oncol Lett. 2018 Oct;16(4):4635-9.

17 Gai S, Lv N, Zhang Q, Zuo Q, Liu J, Huang Q. Multiple Intracranial Aneurysms Caused by Myxoma: Case Report and Literature Review. World Neurosurg. 2020 Jan;133:e376-84.

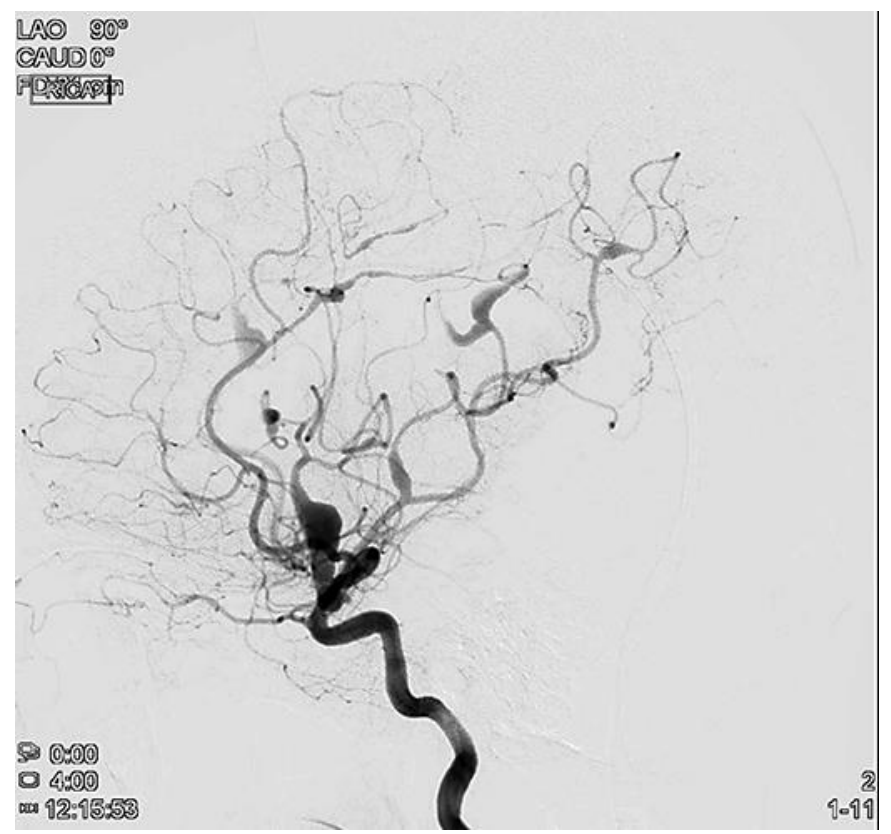

Fig. 1. Right internal carotid angiogram. 
Case Reports in Neurology

\begin{tabular}{l|l}
\hline Case Rep Neurol 2020;12:189-195 \\
\hline DOI: 10.1159/000505390 & $\begin{array}{l}\text { @ 2020 The Author(s). Published by S. Karger AG, Basel } \\
\text { www.karger.com/crn }\end{array}$ \\
\hline
\end{tabular}

Jain et al.: Cardiac Myxoma and Multiple Cerebral Aneurysms

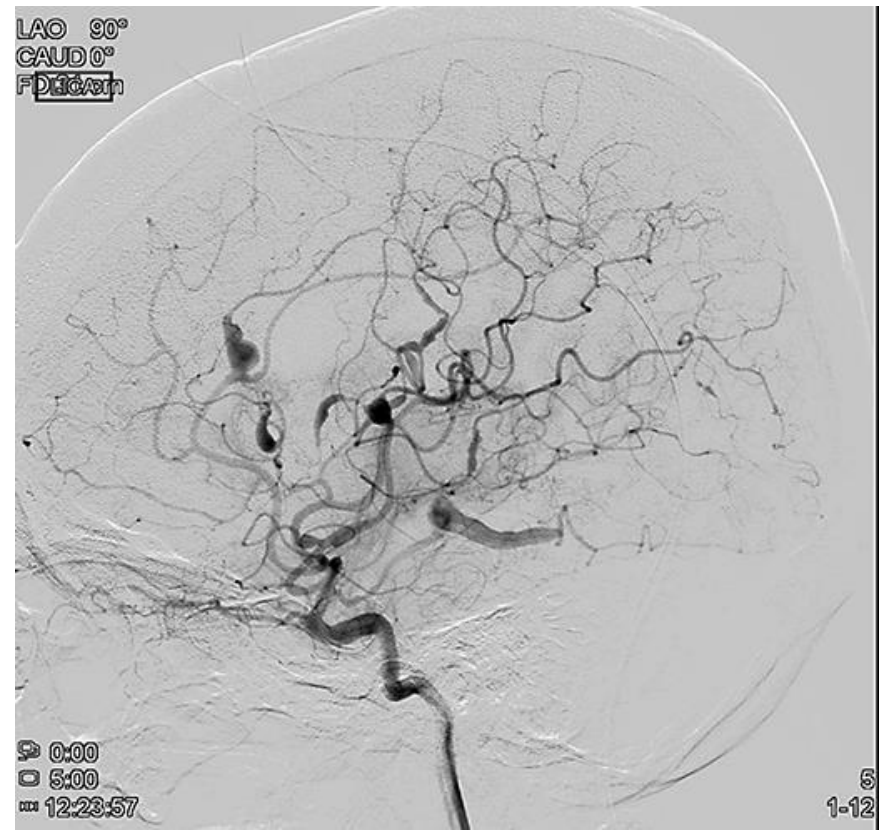

Fig. 2. Left internal carotid angiogram. 